\title{
Experimental Investigation on the Wave Rotor Constant Volume Combustor
}

\author{
Yu Matsutomi ${ }^{1}$ and Scott E. Meyer ${ }^{2}$ \\ Purdue University, West Lafayette, IN, 47907
}

Sameera Wijeyakulasuriya ${ }^{3}$, Zuhair Izzy ${ }^{4}$ and M. Razi Nalim ${ }^{5}$

Indiana University-Purdue University Indianapolis, Indianapolis, IN, 46202

Masayoshi Shimo ${ }^{6}$, Mike Kowalkowski ${ }^{7}$ and Phil H. Snyder ${ }^{8}$

Rolls-Royce North American Technologies, Inc. - LibertyWorks ${ }^{\circledR}$, Indianapolis, IN, 46241

\begin{abstract}
A wave rotor constant volume combustor was designed and built as a collaborative work of Rolls-Royce, Indiana University-Purdue University Indianapolis (IUPUI), and Purdue University. The experiment was designed to operate at rotational speeds of up to $4,200 \mathrm{rpm}$ with air mass flow rates of approximately $18 \mathrm{lbm}$ per second. Initial tests were conducted at $2,100 \mathrm{rpm}$ with ethylene as fuel. The rig was operated with different fuel injection schemes to investigate operational characteristics of the combustor. Successful combustion and pressure gain were achieved over a range of operating conditions.
\end{abstract}

\section{Introduction}

$\mathrm{T}$ he wave rotor constant volume combustor (WRCVC) is a device proposed to accomplish pressure gain combustion for jet propulsion applications. It utilizes unsteady wave motion coupled with constant volume combustion to increase the thermodynamic efficiency of a combustion system. Unlike Pulse Detonation Engine (PDE) based concepts, a detonation process is not required for achieving a pressure gain if combustion is rapid, and the device is designed to operate with near steady inflow and outflow. This concept has promising potential for system integration with conventional compressor and turbine systems without major concerns of unsteady wave interactions. Thus, the WRCVC is considered as a strong competitor to a PDE-hybrid for a pressure-gain combustion turbine engine.

A simplified schematic of a WRCVC is shown in Figure 1. The WRCVC consists of an assembly of multiple cells located annularly within a rotor. Premixed fuel and air are injected into each combustion cell as it rotates through the opening of the seal plate. After each cell is filled (or partially filled) with reactant mixture, both ends of the cell close and the mixture is ignited, creating a constant volume combustion environment. The combustion products are subsequently exhausted through the opening of the seal plate to the manifold. The only components in the WRCVC system exposed to the unsteady combustion cycle are the combustion cells. The inlet and exhaust units will experience nearly steady inflow and outflow from the combustor. Detailed descriptions of the operational modes and their fluid dynamics can be found in Alparslan et. al. ${ }^{1}$

Experimental and theoretical studies of wave rotors with various applications, port configurations, and sizes have been conducted in Europe, the United States, and Japan. Most of the earlier works were done on noncombusting wave rotors, categorized as dynamic pressure exchangers ${ }^{2,3}$. This application has been considered for a variety of systems such as internal combustion engines, gas turbines, and air refrigeration systems. The most successful commercial application of a pressure-exchange wave rotor is the Comprex ${ }^{\circledR}$ supercharger. The device is installed on diesel engine cars, such as the Mazda 626 Capella, which shows better response and operability during acceleration compared to a conventional turbocharger. ${ }^{3}$ Another notable wave rotor effort was the internal-

\footnotetext{
${ }^{1}$ Research assistant, School of Aeronautics \& Astronautics, ymatsuto@purdue.edu, AIAA Student Member.

${ }^{2}$ Managing director, Zucrow Laboratories, AIAA Member.

${ }^{3}$ Research assistant, School of Mechanical Engr., Purdue University, AIAA Student Member.

${ }^{4}$ Research assistant, Department of Mechanical Engr., AIAA Student Member.

${ }^{5}$ Professor, Department of Mechanical Engr., mnalim@iupui.edu, Associate Fellow AIAA.

${ }^{6}$ Method specialist, Design systems engineering, AIAA Member.

${ }^{7}$ Senior Engineer, Installations, AIAA Member.

${ }^{8}$ Consultant Engineer, Propulsion System Integration, AIAA Member.
} 
combustion wave rotor developed by Asea Brown Boveri (ABB) between 1991 and 1994. ${ }^{4}$ The rig consisted of 36 combustion cells placed annularly over a $200-\mathrm{mm}$ diameter rotor. The rotor operated as a 3-port cycle which consisted of an inlet with stratified fuel distribution, and high and low-pressure outlets. Spark plugs were used for engine start-up, and the hot gas was routed back upstream to the unburned gas mixture for self-sustained ignition. The rig exhibited a number of unexpected problems, but possible solutions were studied and several design modifications have been suggested. Considerable improvement was made with respect to rotor seals throughout the duration of the program, although high pressure runs were not possible. The project was discontinued in 1994 as there appeared to be no market in the targeted small engine co-generation field to warrant an exhaustive development effort. An extensive review of wave rotor combustion research can be found in papers from Akbari et. al. $^{5,6}$

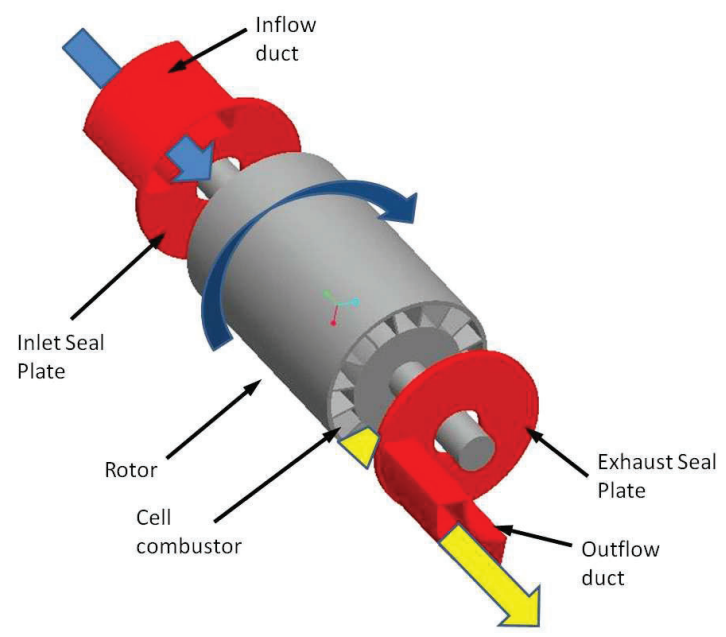

Figure 1. A simplified schematic of a WRCVC.

Recently a WRCVC technology demonstrator was designed and built as a collaborative effort of Rolls-Royce, Indiana University-Purdue University Indianapolis (IUPUI), and Purdue University (Figure 2). An initial series of tests were conducted to investigate operational characteristics of the combustor. Successful combustion cycles were achieved, and the viability of the concept for use in a pressure-gain engine has been demonstrated. The purpose of this paper is to summarize experimental results from initial operability tests and show the progress of the project as a follow up to the author's previous paper?

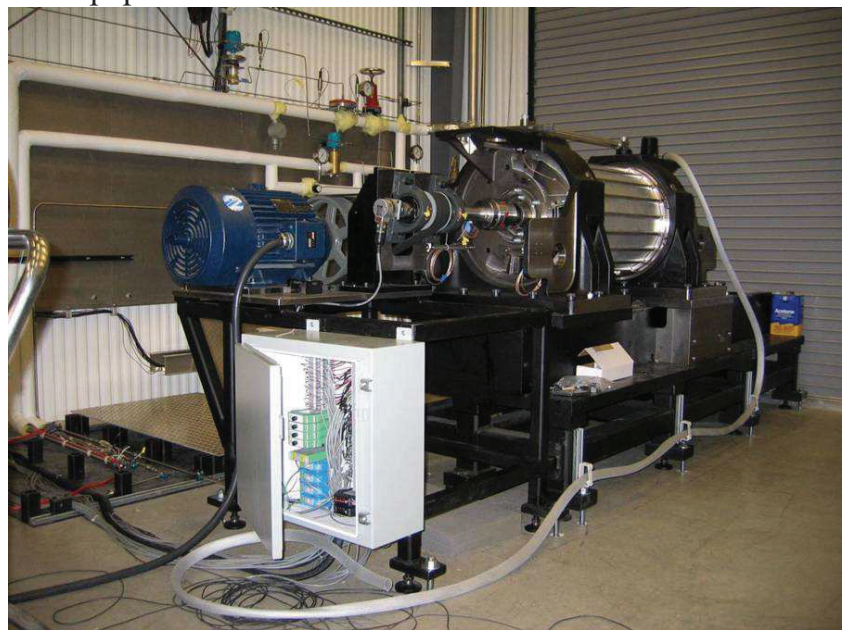

Figure 2: WRCVC experimental rig at Purdue University.

\section{Experimental Rig}

The WRCVC test stand is housed in the High Pressure Lab Annex at the Purdue University Zucrow Laboratories. The test stand is operated as a direct connect configuration with the facility air system, and the 
exhaust of the rig is ducted to ambient air. Air supplied to the test WRCVC was at near ambient temperature for initial testing, but air heating is planned for future tests. The test combustor, therefore, operates at nearly atmospheric inlet conditions. A cutout view of the experimental rig assembly is shown in Figure 3. The main components of the rig are the inlet, exhaust, rotor, seal plates, ignition source, fuel injectors, and electrical motor. The electrical motor was used to provide necessary torque for the rotor. In a real engine, the rotational power can be taken from the turbine output, or by shaping the combustor so its inflow and exhaust produce necessary rotational torque. Gaseous fuels such as ethylene and propane were used to eliminate vaporization effects and reduce mixing effects. The porting for initial tests was designed to match an operating speed of 2,100 rpm and mass flow rates of approximately $9.5 \mathrm{lbm} / \mathrm{sec}$. Experiments were run for short combustion durations (on the order of 2-3 seconds) to keep the rotor temperature within the design limit, which was demonstrated to be sufficient time to establish a repeating cycle.

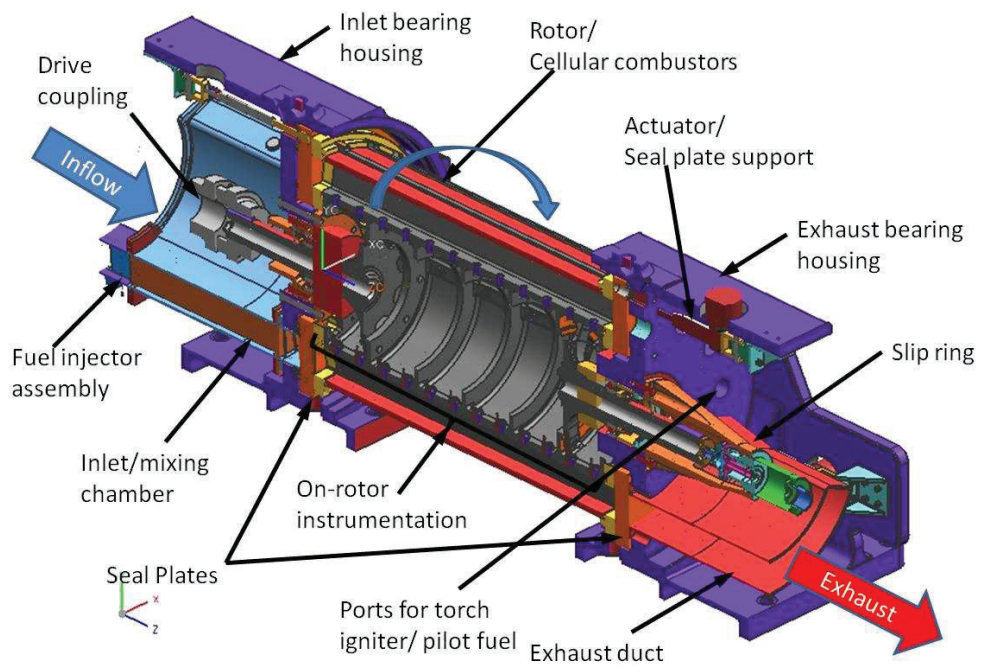

Figure 3: A cut-out view of the WRCVC test article.

The inlet chamber is located upstream of the rotor and mounted on the inlet seal plate. The function of the inlet chamber is to provide mixing length for injected fuel and air while allowing the flow to turn. Inlet seal plate has a 104-degree opening to allow reactant mixture to enter the combustion cells. The flow is turned through inlet guide vanes to match the rotor tangential velocity.

The fuel injection tubes are located on the upstream side of the inlet chamber. The fuel injector assembly has the same cross sectional shape as the inlet chamber and has fuel injectors in 15 circumferential locations. Fuel distribution is controlled by the number and location of active fuel injectors. Injectors are designed to promote a uniform reactant mixture at the entrance to the rotor.

The rotor consists of 20 circumferentially located combustion cells, at mean radius of 9 inches. The approximate size of each combustor is $2 \times 2.5 \times 31$ inches. Select combustion cells are instrumented with thermocouples, pressure transducers, and ion probes along the flow path.

Seals between stationary parts and the rotor are established by seal plates located at both ends of the rotor. The seal plates and rotor are set in close proximity to minimize leakage. Other sealing methods, such as rub seals and brush seals, were considered, but the proximity gap provided a sufficient seal for the initial tests. Leakage flow analysis through a proximity gap of a wave rotor is discussed by Akbari et. al ${ }^{8}$. An external casing for leak containment was not installed on the current configuration.

The exhaust duct was mounted on the opening of the seal plate. It routes the exhaust products away from the test article and as currently designed does not attempt to capture thermodynamic work available in the exhaust gases. The exhaust boundary of the rotor is effectively ambient.

A propane/air torch igniter with choked outflow has been developed as the ignition source for the rig. The igniter was mounted on the exhaust end seal plate. The torch igniter was designed to operate continuously regardless of the unsteady events occurring within the WRCVC passages. The continuous operation of the igniter eliminates the need for motion synchronization with the rotor. The torch igniter chamber was cooled with an air 
jacket and the film coolant is injected into the chamber prior to the nozzle contraction. It was designed to operate at approximately one percent of the engine mass flow.

\section{Measurement and Control}

The WRCVC facility was equipped with a set of data acquisition and control systems located near the experiment. The main data were logged through a 16-bit data system, which had a maximum total sample rate of 333,000 samples per second. 128 channels were currently operational, and data were logged at 500 samples per second per channel. This included all voltage signals from pressure transducers, thermocouples, control feedback devices, accelerometers, and proximity probes. Additionally, 32 channels were available for 12-bit high frequency data acquisition. High frequency data was typically logged at 200,000 samples per second per channel. The main and high frequency data systems were synchronized by a trigger signal originating from the main data system. A total of 32 digital and 16 analog outputs were available for control during test operations. The control channels can be accessed through a virtual control panel developed using LabVIEW. The test sequence can be automated with better than one millisecond accuracy, and abort criteria was available on all operational channels. Test operators conducted experiments from a remotely located control room to assure safety.

The WRCVC test article was instrumented with pressure transducers, thermocouples and ion probes. Instrumentation locations are summarized on the unrolled view of the WRCVC shown in Figure 4. Flow was directed from left (inlet) to right (exhaust). The $\theta$-axis depicts angular location, with zero corresponding to the bottom dead center of the rig. Cell 9 is physically adjacent to cell 10 . The inlet section existed on the $\theta$-axis between 0 and 104 degrees. The exhaust section existed on the $\theta$-axis between 316 and 75 degrees. The torch igniter was installed at the 180 degree location on the exhaust seal plate for the initial tests. The letters "T," "P," and "I" correspond to thermocouple, pressure measurement, and ion probe locations, respectively.

The angular location of the rotor was measured with an incremental encoder connected to a counter card. The angular data were logged at the same frequency, and triggered at same time, as the high frequency data acquisition system to ease comparisons between rig measurements and rotor position.

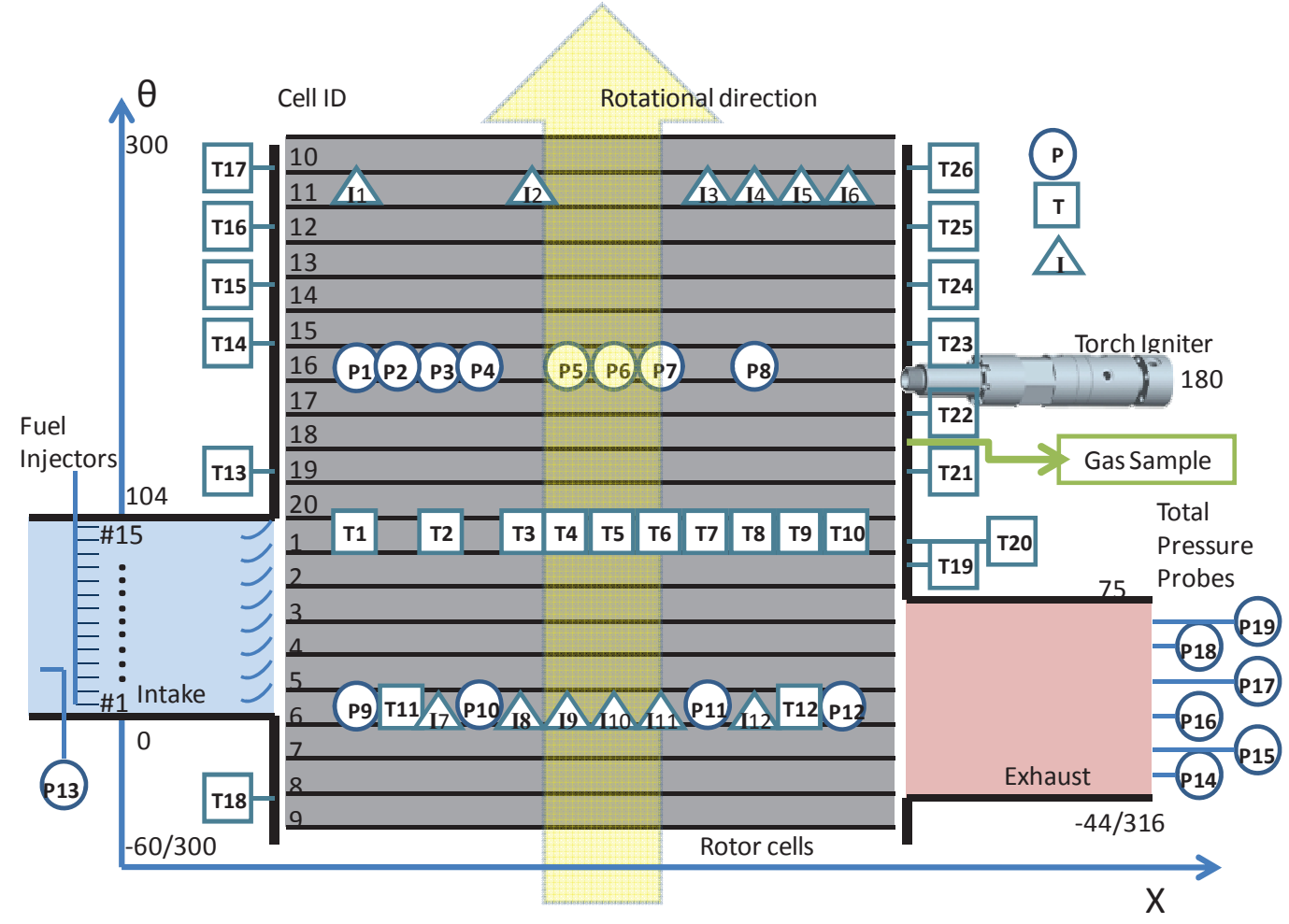

Figure 4: An unrolled view of the rotor and its instrumentation.

\section{Experimental Results}


A series of combustion tests were conducted after verifying the operation of torch igniter and to assess the leakage rate of the test article. The main objective of the initial combustion tests was to map out successful operating conditions with different fuel injection locations and equivalence ratios. In general, the test article was able to sustain combustion over a wide range of settings. At the optimum operating conditions, the combustor produced stable steady exhaust plume and operated smoothly throughout ignition and shutdown.

First, results from near optimum operational conditions are presented. The test conditions were: air flow rate of $9.6 \mathrm{lbm} / \mathrm{sec}$, ethylene flow rate of $0.51 \mathrm{lbm} / \mathrm{sec}$, first 9 active injection tubes out of 15 total injectors, $2,100 \mathrm{rpm}$ rotor speed, and fuel flow for one second duration. For the given fuel injection scheme the ideal local equivalence ratio per fuel tube is 1.31 . The ideal local equivalence ratio was calculated as follow.

$$
\phi_{\text {local }}=\frac{\left.\frac{\text { Air }}{\text { Fuel }}\right)_{\text {stoich }}}{\frac{\text { Air }}{\text { Fuel }}\left(\frac{\# \text { injector }_{\text {active }}}{\text { \#injector }_{\text {total }}}\right)}
$$

The original inlet design had partitions in the inlet duct to obtain axial stratification of the combustible mixture. However, the partitions were excluded in the initial tests discussed in this paper, and the fuel injected from each active injector was allowed to mix and interact. The average measured inlet total pressure was 21.7 psi during the combustion process.

\subsection{Rotor Measurements}

On-rotor temperature measurements from the stated test are presented in Figure 5. The measurement was taken with $1 / 16$ inches type-K thermocouple intruding into the combustion chamber from the inner wall approximately $1 / 8$ inches. The fuel valve was actuated between 214 and 215 seconds. There was a couple hundred milliseconds delay between the time of valve actuation and the first sign of ignition due to the finite time for the fuel to travel from the injectors to the rotor. The on-rotor thermocouples recorded high temperatures over most of the channel length. At fuel cutoff, the temperature was still rising rapidly. The peak rotor temperature of near 1,500 $\mathrm{F}$ was observed for the longer combustion test (approximately three seconds) with similar test conditions. These thermocouples were exposed to the combustion gas and cold reactant periodically, and the measured values represent averaged temperatures over the cycle. According to the Q1D simulation [companion paper, Elharis 2010], the contact surface for pure air and reactant mixture lies at 14.7 inches from the inlet, near T4 prior to combustion. During combustion the contact surface location moved as far upstream as the 4.2 inches location from inlet, and oscillated around T2 location.

The exhaust seal plate temperature showed a higher value than that recorded in the rotor (Figure 6). The highest temperature was measured at T23, directly downstream of the torch igniter. Interestingly, the location of the highest temperature varied depending on the test conditions. At the off-design, long duration (three second) test, the highest temperature of over $2,000 \mathrm{~F}$ was measured at T24 and T25. Thermocouple at T22 also measured elevated temperature, indicating upstream propagation of combustion flame and/or torch igniter exhaust. The temperature measurements directly after the exhaust, T19, T20 and T21, showed no temperature change during the operation. The combustion products were completely exhausted every cycle, and it is likely some fresh reactants were overfilled and spilled. The Q1D simulation indicated inflow spillage of approximately $7.1 \%$ for this condition.

A relatively small temperature rise was measured with thermocouples on the inlet seal plate. The temperature measured at T15 was slightly higher than at the location directly after the torch igniter, T14, although the temperature at T14 was lower than T15 prior to ignition (torch igniter without fuel injection). Compared to the close measurement among T14, T15 and T16, the temperature measured at T17 and T18 were clearly lower than these three. 


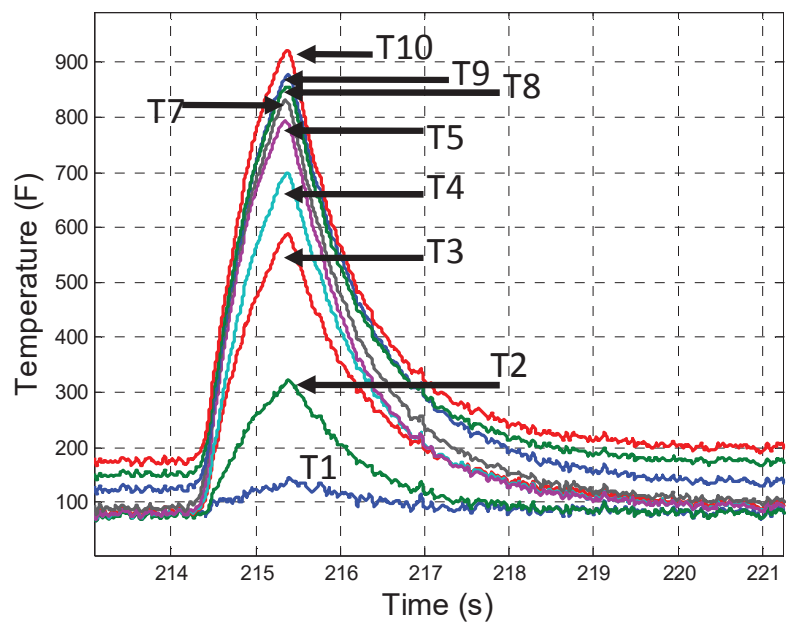

Figure 5: On-rotor temperature measurement for $2100 \mathrm{rpm}$, with air flow $(9.6 \mathrm{lbm} / \mathrm{sec})$, combustion test, 0.51 $\mathrm{lbm} / \mathrm{sec}$ ethylene injected in the first $60 \%$ of inlet opening.
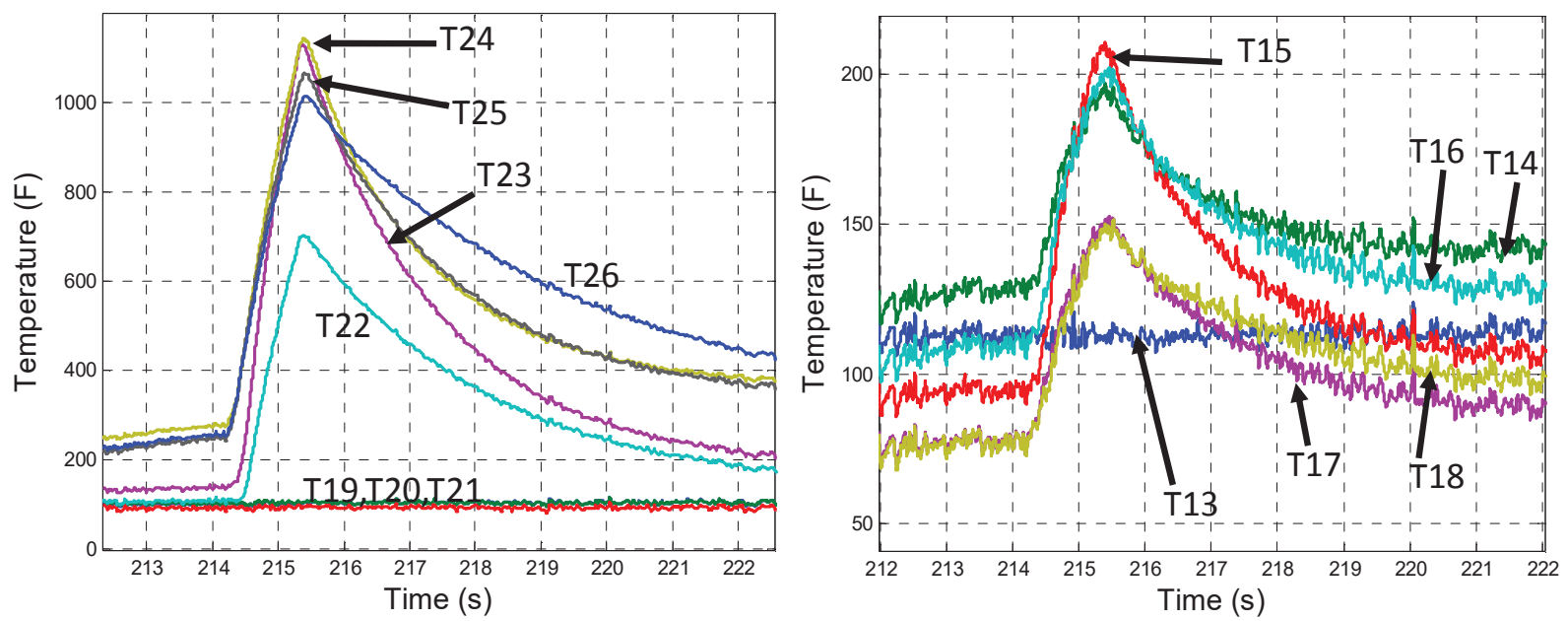

Figure 6: Exhaust(LEFT)/Inlet(RIGHT) seal plates temperature measurement for $2100 \mathrm{rpm}$, with air flow $(9.6 \mathrm{lbm} / \mathrm{sec})$, combustion test, $0.51 \mathrm{lbm} / \mathrm{sec}$ ethylene injected in the first $60 \%$ of inlet opening.

The on-rotor pressure measurement over one cycle of the same test is presented in Figure 7. Each pressure datum is offset respectively to represent the physical location of the measurement along the rotor channel. Each Xaxis grid corresponds to 100 psi difference. Some apparent pressure peaks can be traced over different locations to identify the motion of the pressure waves. These peaks are identified with arrows in the plot. Based on the acoustic speed of the cold air, an approximately 29 degree rotation occurred before a pressure disturbance traveled the entire length. The largest pressure rise of approximately 90 psi was measured near the inlet seal plate, slightly after the torch igniter location. The pressure in the rotor plateaued between 60 to 80 psia after combustion. This pressure level was lower than the expected. Pressure loss due to the leakage affected the initial and final rotor pressure. The current set of testing was conducted with relatively loose leakage control. Improved leakage mitigation and control are planned for future test.

The pressure profile at each location was very repeatable at P2, P3, P4 and P6 locations. The variations in the pressure data between different channels were also small. Pressure measurements at P4 and P10, which were located at the same axial distance, 180 degree apart, were almost identical in their pressure profiles (Figure 8). The plot includes pressure profiles from five consecutive cycles from each location. Despite the relatively short run duration, the pressure profile indicated the system operated at near limit cycle in fluid dynamic terms. The test article was designed to run only short duration for thermal considerations. 


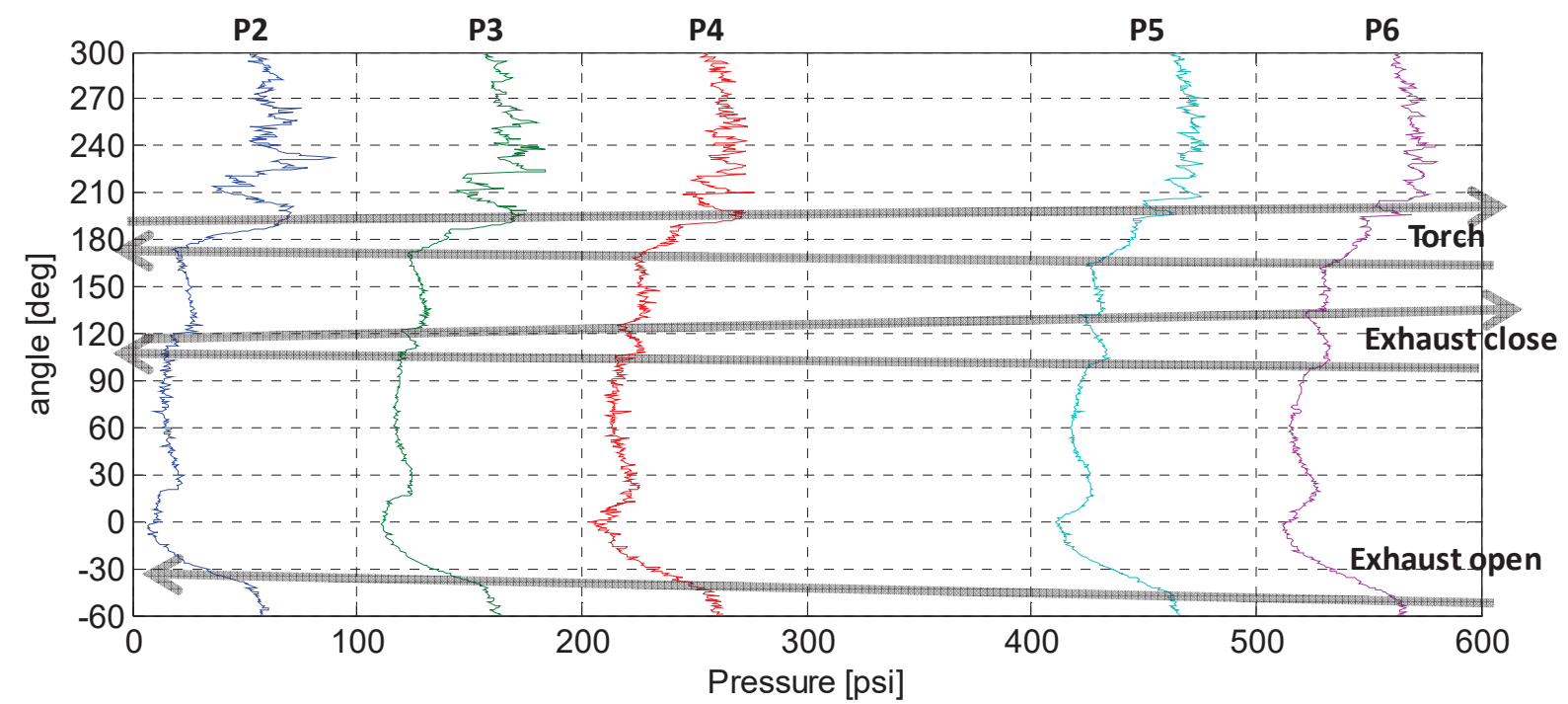

Figure 7: On-rotor pressure measurement during the combustion. Grid represents 100 psi divisions. Each measurement is offset in $\mathbf{x}$-axis to represent the physical axial location on the rotor. Arrows follows approximate location of the same pressure disturbance.

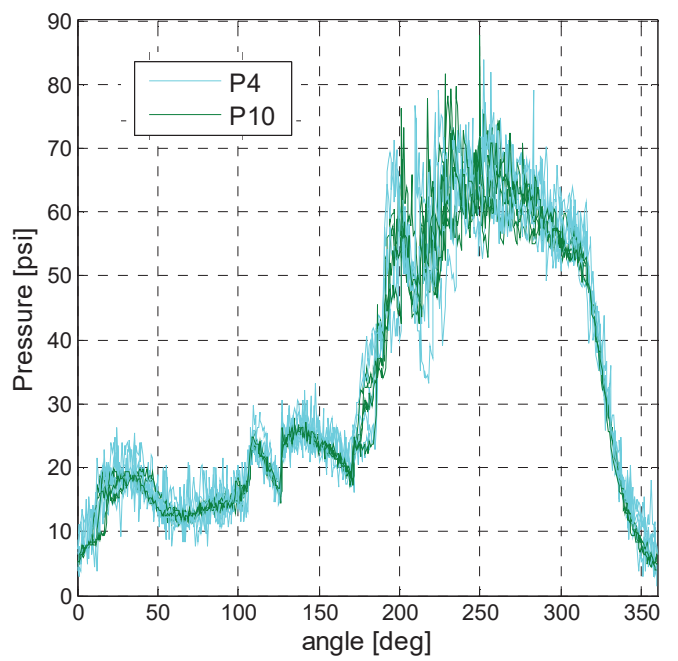

Figure 8: On-rotor pressure measurement at P4 and P10 during combustion process. Each measurement location contains five consecutive cycles.

The ion probe measurements over several cycles are plotted in Figure 9. The Y-axis corresponds to the angular location and the $\mathrm{X}$-axis corresponds to the voltage signal. The measurement from the each location is offset in $\mathrm{X}$ axis to represent the physical locations along the rotor length. Compared to the pressure measurement, the ion probe measurement was not as repeatable across cycles. This lack of repeatability was mainly due to the nature of the instrumentation. The ion probe requires direct contact with an active combustion process, but the sensor only protrudes $1 / 4$ inches into the channel. Three dimensional variation in the flame structure can influence the measurement significantly. In some cases, multiple peaks were recorded at one location. This was due to the pressure wave oscillating the gas and flame front in the chamber. The effect was most prominent near the center of the chamber.

The reaction zone indicated by the ion probes showed that the combustion flame propagated much faster than originally expected. The axial flame speed was on the order of $600 \mathrm{ft} / \mathrm{sec}$ based on the peak measurement. This was more than half of the acoustic velocity and is categorized as a fast deflagration process. The strongest signal was 
recorded around 19 location, which is near the middle over the rotor length. A nearly negligible signal was recorded at the I7 location, which indicates no active combustion process occurred at this location.

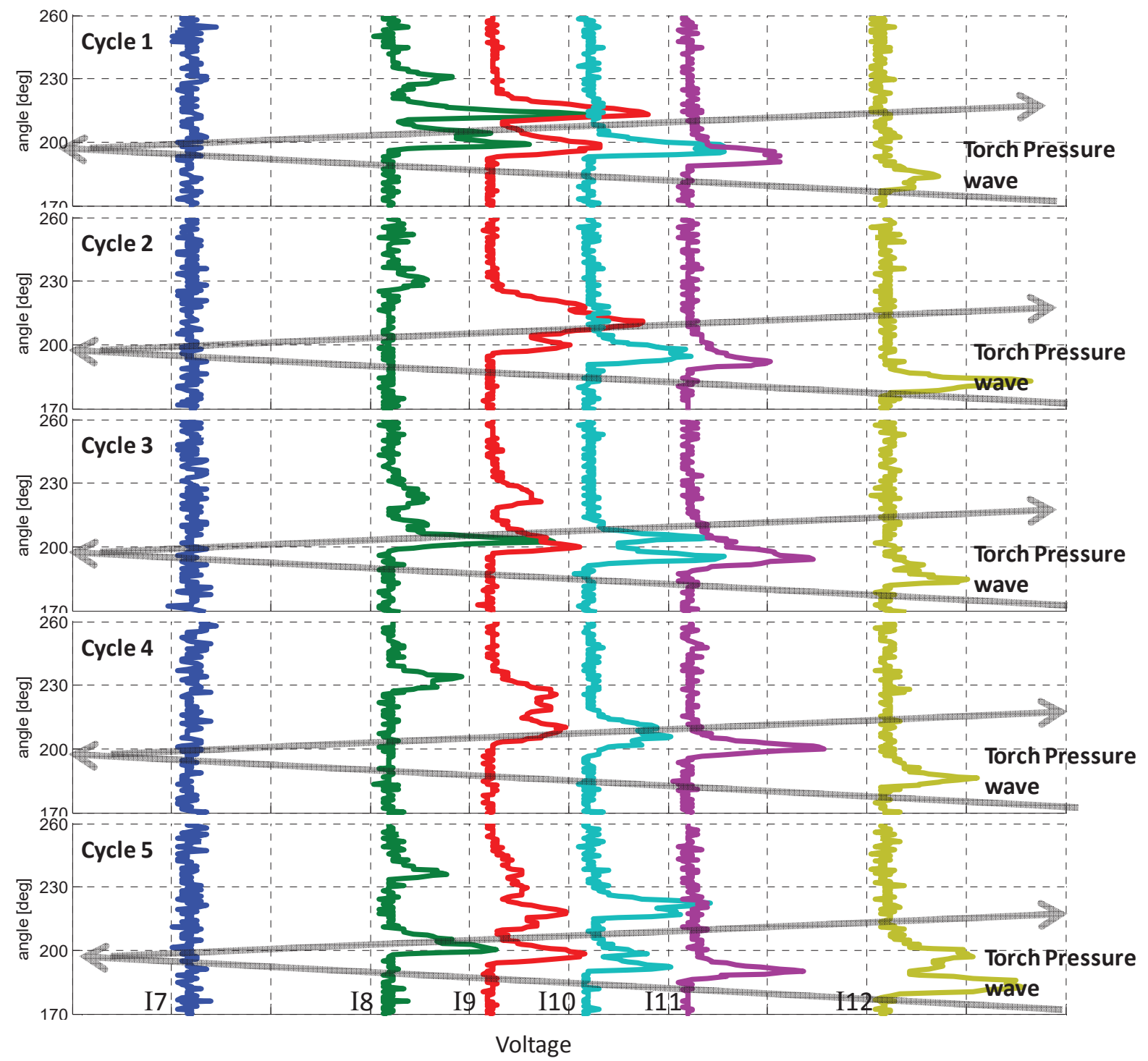

Figure 9: On-rotor Ion probe measurement during combustion process. The data is from five consecutive cycles. . Each measurement is offset in $\mathbf{x}$-axis to represent the physical axial location on the rotor. The grid represents same unit voltage in $x$-axis.

\subsection{Inlet/Exhaust Measurements}

The inlet total pressure measurement from the same previous combustion test is presented in Figure 10. Nominal inlet total pressure was about 22.25 psi prior to torch ignition. As the torch igniter lit, inlet total pressure dropped approximately $0.5 \mathrm{psi}$. The mass addition from the torch igniter effectively creates a pumping effect similar to the pressure exchanger cycle. Combustion started when the fuel flow was initiated at 214 seconds. It was unexpected that the inlet pressure did not change much when the combustion started. A larger pressure drop with a stronger pumping effect was expected during the combustion process. In order to fully assess the effect of combustion on the inlet pressure, the effect of the fuel flow shall be carefully considered. The effect of the fuel flow alone can be observed around 198 seconds in the plot. At this point, the fuel flow was activated prior to combustion to release any unwanted fuel accumulation in the fuel plumbing. The fuel flow rate observed during this period was 
approximately the same as during the combustion test. During this period, the inlet total pressure increased approximately $1.0 \mathrm{psi}$ from the nominal pressure due to the fuel injection. The system should experience a similar pressure rise during combustion process due to the fuel addition. If the effect of fuel addition was considered, the inlet pressure decrease during combustion could be approximately 1.5 psi compared to pre-combustion torch igniter operation.

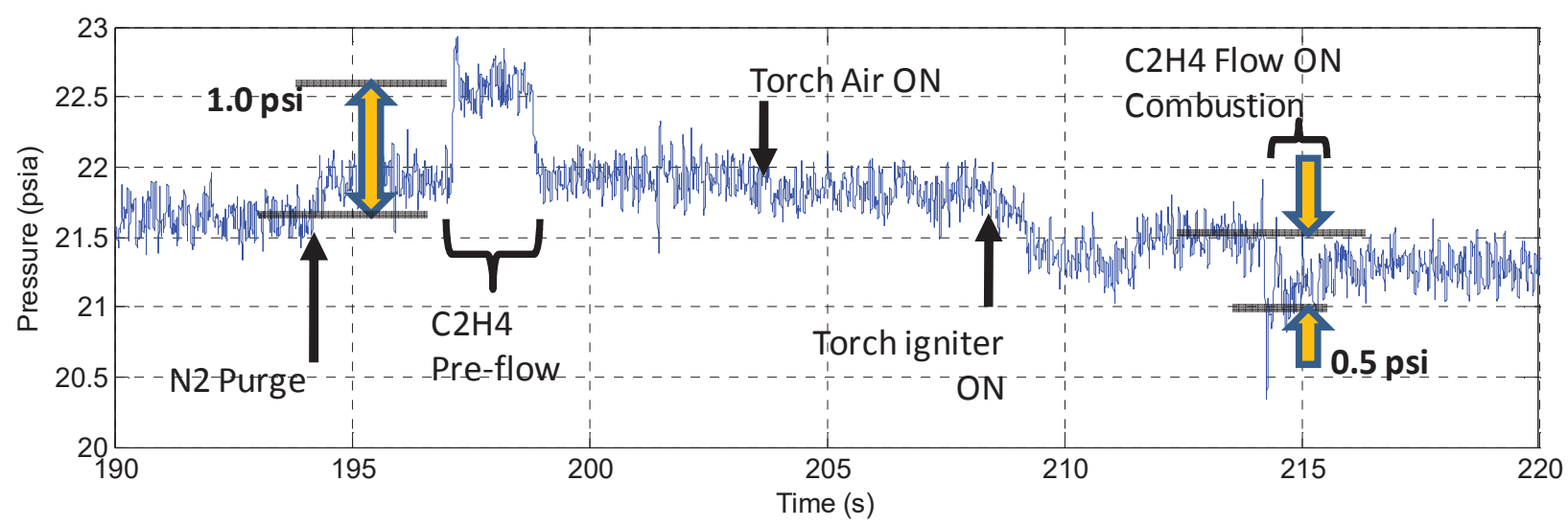

Figure 10: Inlet total pressure measurement.

The total pressure of the exhaust flow was measured with six pressure probes located at exit of the exhaust duct. The exhaust duct was 24 inches long from the exhaust seal plate. The pressure measurement during the combustion period is plotted in Figure 11. The data were filtered at $10 \mathrm{~Hz}$ to present the pressure trend clearly. When combustion was initiated, the first total pressure measurement (-34 degree location) showed a large jump. The average pressure measured at this location during combustion period was 26.9 psi. Assuming a static pressure of $14.7 \mathrm{psi}$, the total to static pressure ratio of 1.83 resulted in a Mach number of 1.03 with $\gamma$ of 1.2 , and 0.97 with $\gamma$ of 1.4. Compared to this high Mach number, the adjacent measurement at -15 degree location indicated a very low Mach number flow. There existed a very high velocity gradient between these two measurements. Except for the first total pressure probe, all of the pressure measurements showed decreases in pressure during the combustion process. The pressure measurement prior to combustion included the effect from the torch igniter.

The area averaged total pressure of the exhaust flow was 18.1 psi. However, the area average total pressure did not correspond to any conservative property of the flow and does not have physical meaning. Temperature measurement was not available in the exhaust plume, so the mass averaged total pressure could not be resolved. This highlights the necessity for additional measurements to understand the exhaust flow properties in future testing.

The sampling rate of the exhaust pressure probes was limited to $500 \mathrm{~Hz}$ for the current testing. Therefore, their frequency contents were resolved only up to $250 \mathrm{~Hz}$. Within this frequency range, no distinctive frequency content was observed. Based on the operational speed of the rotor, more active frequency content is expected near $700 \mathrm{~Hz}$. The pressure measurement at -34 degrees had peak to peak pressure of $+/-4$ psi from the average pressure of 26.9 psi. 


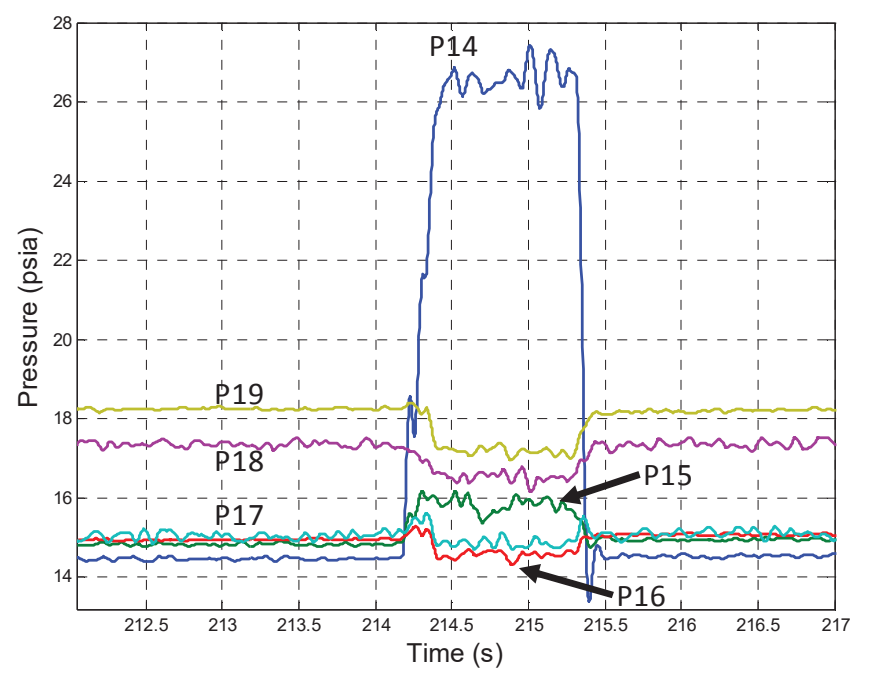

Figure 11: Exhaust total pressure measurement. $10 \mathrm{~Hz}$ filtered

\subsection{Rotor Torque Measurement}

Torque input to the test article was measured by the variable frequency drive of the driving electrical motor. The torque measurement provided insight into rotor response to the air inflow and combustion process. The incoming flow to the rotor was turned by the inlet guide vanes to match the tangential velocity of the rotor. At the design condition, the rotor should not require any torque to accelerate or decelerate air flow.

Figure 12 shows torque measurement, rotor rpm and air mass flow rate for the combustion test. The rotor reached its target RPM of 2,100 at approximately 90 seconds into the test sequence. At this point, the torque was 56 $\mathrm{ft}-\mathrm{lb}$ in order to overcome mechanical friction and air resistance. As the air flow rate increased, the torque input continuously decreased while the rotor rpm was kept constant. At the full air flow rate of $10 \mathrm{lb} / \mathrm{sec}$, the required torque input was $23 \mathrm{ft}-\mathrm{lb}$ lower than that without the air flow. This implies that the tangential velocity of the inflow air was faster than the rotor speed and the inflow was producing work on the rotor. At 214 seconds, combustion was initiated and a slight decrease in rotor $\mathrm{rpm}$ and a sudden increase in the torque input were observed. Since the combustion duration was limited, the steady state torque value was not achieved. The increased torque requirement was reasonable if the turning vane design was well matched for the combustion condition. At the design point, the inflow air should not exert work on the rotor, and the required torque should settle around $56 \mathrm{ft}-\mathrm{lb}$ - the value measured at the no-flow condition.

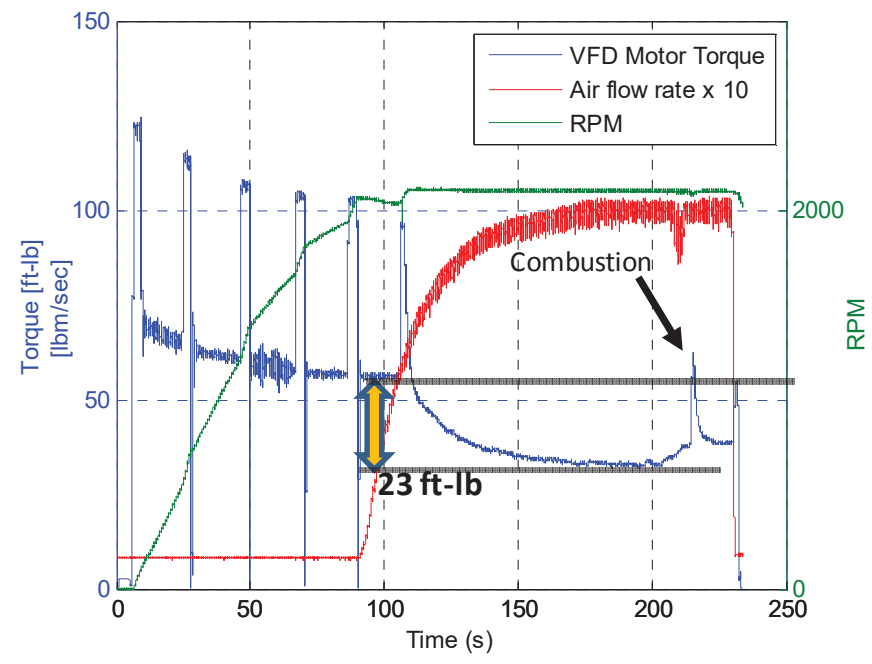

Figure 12: Motor torque and rpm measurement. 


\subsection{Effect of Fuel Injection}

A series of tests were conducted to characterize WRCVC operation with different fuel injection schemes. The fuel injector distribution and local equivalence ratio were varied. First, the effect of number of active fuel injector is presented in Figure 13. The peak pressure from the experiment was averaged over several cycles. If the test condition produced inconsistent combustion, the failed cycles were excluded from the average. There were total of 15 fuel injector locations available along the inlet opening. All the active fuel injectors were placed in the first available locations of the inlet opening (closest to zero degree (Figure 4)). These experiments were conducted with air mass flow rate of 8.2 to $8.3 \mathrm{lb} / \mathrm{sec}$ and local equivalence ratios between 1.53 and 1.58. All the test conditions had consistent combustion cycles except the 7-injector case. Successful combustion percentage of the 7-injector case was $82 \%$.

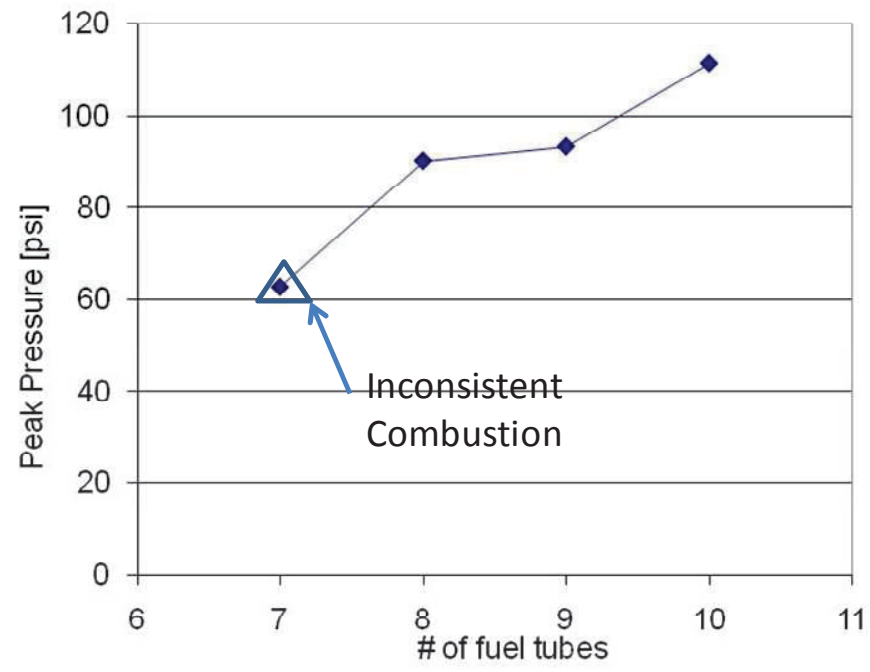

Figure 13: Peak pressure during combustion process for different number of active fuel injector tubes. Local equivalence ratio is approximately 1.55 and air mass flow rate is $8.2 \mathrm{lb} / \mathrm{sec}$ for all data points.

The effect of the local equivalence ratio is presented next. The averaged peak pressure for different local equivalence ratio is plotted in Figure 14 (LEFT). The experimental result shows monotonic increases of peak pressure with local equivalence ratio. It is important to note that the inlet duct was used without partitions, which ware in the original design. There was no restriction to confine fuel in the prespecified volume. Therefore, there was no distinct separation between reactant mixture and the buffer air. The actual fuel fill fraction was expected to be higher and the local equivalence ratio to be lower than specified in the plot due to this fuel migration into the air buffer.

For all the test conditions conducted, combustion was more successful with relatively higher local equivalence ratios. The percentage of successful combustion cycles is plotted in Figure 14 (RIGHT). The local equivalence ratio of near 1.4 appears to be the minimum equivalence ratio for fully successful combustion for the air flow rate of $8.2 \mathrm{lbm} / \mathrm{sec}$. The tendency for the high equivalence ratio may have resulted from the mixing of the new and remaining gas in the rotor. As the inflow enters the rotor, the flow mixed with the gas remaining in the rotor. The magnitude of the mixing varied with the amount of turbulence and formation of a vortex as the inflow entered. The tendency toward high equivalence ratio implied this mixing was rather strong, and the equivalence ratio near the contact might be significantly lower than anticipated. An effort was made to take gas samples at the exhaust seal plate to examine the local equivalence ratio prior to the torch ignition. The result showed consistently low equivalence ratio (between 0.4 to 0.6 ) despite the input ideal local equivalence ratio of 1.26 to 1.47 . There is large uncertainty in the current gas sample data, and it will require further testing to reach any conclusion about the local equivalence ratio. 

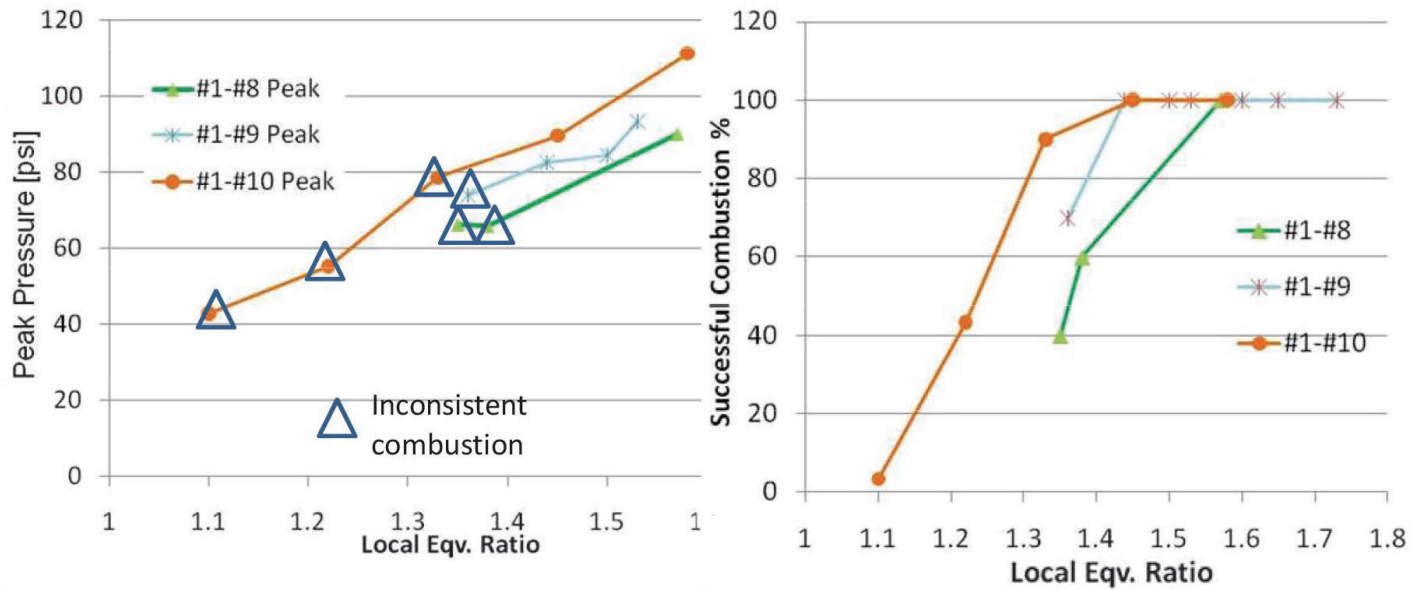

Figure 14: (LEFT)Peak pressure measured during combustion process for different equivalence ratio. (RIGHT) Percentage of the successful combustion cycles. Air mass flow rate is approximately 8.2 for all data points.

\section{Conclusion}

The test results from the WRCVC are presented. The test article operated reliably over the range of test conditions and has shown viability of the concept. There has been only a limited amount of experimental data available on the WRCVC technology before this experiment, and the current set of data will be the first publically available data on the WRCVC experiment. The results will be used to improve modeling tools such as the Q1D WRCVC model [companion paper, Elharis 2010] ${ }^{9}$.

\section{References}

${ }^{1}$ Alparslan, A., Nalim, R. M., and Snyder, P. H., "Wave Rotor Combustor Test Rig Preliminary Design," Proceedings of IMECE04, IMECE2004-61795, November, 2004

${ }^{2}$ Shreeve, R. P., and Mathur, A., Proceeding ONR/NAVAIR Wave Rotor Research and Technology Workshop, Report NPS67-85-008, Naval Postgraduate School, Monterey, CA, 1985

${ }^{3}$ P. Akbari, M.R. Nalim, \& N. Müller, "A Review of Wave Rotor Technology and Its Applications," ASME Journal of Engineering for Gas Turbines \& Power, v.128, no.4, pp.717-735, Oct 2006.

${ }^{4}$ Weber, R., "A Pressure-Wave Machine with Integrated Constant-Volume Combustion," Swiss Energy Research Report 1977-1997,National Foundation of Energy Research, Switzerland, Project No. 426, 1997, pp. 142-153.

${ }^{5}$ Akbari, P., Szpynda. E., and Nalim, M. R., "Recent Developments in Wave Rotor Combustion Technology and Future Perspectives: A Progress Review," AIAA Paper 2007-5055, 43rd AIAA/ASME/SAE/ASEE Joint Propulsion Conference \& Exhibit 8 - 11 July 2007, Cincinnati, OH

${ }^{6}$ Akbari, P., and Nalim, M. R., "Review of Recent Developments in Wave Rotor Combustion Technology," Journal of Propulsion and Power, 0748-4658 vol. 25 no. 4, 2009

${ }^{7}$ Matsutomi, Y., Hein, C., Lian, C., Meyer, S., Merkle, C. and Heister, S., "Facility Development for Testing of Wave Rotor Combustion Rig," AIAA-2007-5052, 43rd AIAA/ASME/SAE/ASEE Joint Propulsion Conference and Exhibit, Cincinnati, OH, July 8-11, 2007

${ }^{8}$ Akbari, P., Nalim M. R., Donovan, E. S. and Snyder, P. H., "Leakage Assessment of Pressure-Exchange Wave Rotors," AIAA Journal of Propulsion \& Power, vol. 24, no. 4, Jul-Aug 2008.

${ }^{9}$ Nalim, M. R., Elharis, T. M., Wijeyakulasuriya, S. D. and Izzy, Z., "Wave Rotor Combustor Aerothermodynamic Design and Model Validation based on Initial Testing," $46^{\text {th }}$ AIAA/ASME/SAE/ASEE Joint Propulsion Conference and Exhibit, Nashville, TN, 